\title{
Anabases
}

ANABASES Traditions et réceptions de l'Antiquité

$25 \mid 2017$

Varia

Sophie BASCH (éd.), Portraits de Victor Bérard. Actes du colloque international organisé à l'École française d'Athènes (5-6 avril 2013)

\section{Annick Fenet}

\section{OpenEdition}

\section{Journals}

Édition électronique

URL : http://journals.openedition.org/anabases/6117

DOI : 10.4000/anabases. 6117

ISSN : 2256-9421

Éditeur

E.R.A.S.M.E.

Édition imprimée

Date de publication : 1 avril 2017

Pagination : 275-276

ISSN : 1774-4296

\section{Référence électronique}

Annick Fenet, « sophie ваsсн (éd.), Portraits de Victor Bérard. Actes du colloque international organisé à I'École française d'Athènes (5-6 avril 2013) », Anabases [En ligne], 25 | 2017, mis en ligne le 01 avril 2017 consulté le 20 janvier 2021. URL : http://journals.openedition.org/anabases/6117 ; DOI : https:// doi.org/10.4000/anabases.6117

Ce document a été généré automatiquement le 20 janvier 2021.

(c) Anabases 


\title{
Sophie BASCH (éd.), Portraits de Victor Bérard. Actes du colloque international organisé à l'École française d'Athènes (5-6 avril 2013)
}

\author{
Annick Fenet
}

\section{RÉFÉRENCE}

Sophie BASCH (éd.), Portraits de Victor Bérard. Actes du colloque international organisé à l'École française d'Athènes (5-6 avril 2013)

Athènes, École française d'Athènes (Mondes méditerranéens et balkaniques 6), 2015,

320 p.,

59 euros / ISBN 978-2-86958-275-0

Heureux qui comme Victor Bérard (1864-1931) a pu suivre ses rêves et s'élancer des rives de sa Bienne natale vers les rivages de la Méditerranée! La superbe photo de couverture, montrant l'archéologue à bord de son cotre, une carte marine à la main, invite à la redécouverte de ce fameux helléniste, connu par des générations de lecteurs comme traducteur français et explorateur de l'épopée homérique. Sophie Basch - déjà éditrice dans les collections de l'ÉfA de deux autres volumes tout aussi stimulants sur l'influence de la Grèce dans la littérature et les arts français de la III ${ }^{\mathrm{e}}$ République $^{1}$ - a convoqué encore ici une palette alléchante de spécialistes pour décrire les multiples facettes de ce savant géographe et antiquisant qui, comme beaucoup de ses confrères contemporains, était impliqué dans la politique et géopolitique, locale et surtout internationale, de son temps. Ce parcours exceptionnel est d'abord raconté, à l'aide d'archives et de traditions familiales, par des descendants (Étienne et Reine-Marie Bérard, p.11-39). Vu côté science, V. Bérard constitue une haute figure de l'école républicaine : Jurassien d'origine modeste, repéré par l'inspecteur de l'enseignement 
primaire, il devient interne au lycée départemental puis est envoyé comme élève boursier à Louis-Le-Grand à Paris. Il intègre l'ENS (promotion 1884) puis l'École française d'Athènes (promotion 1887) ; répétiteur à l'ENS (1891-1896), il dispense ensuite un enseignement de géographie ancienne à la quatrième section de l'École pratique des hautes études, d'abord comme maître de conférences (1896-1908) puis comme directeur d'études (1908-1931), ainsi que de géographie à l'École navale (1896-1914). En 1899, il épouse une des filles de l'éditeur Armand Colin, Alice, malgré l'hostilité de ce dernier ; leur dernier enfant, Jean, suivra comme on le sait la carrière paternelle. L'œuvre odysséenne de V. Bérard, depuis plusieurs décennies critiquée, est ici mise en perspective et expliquée : son édition du texte homérique, " épurée » et "bouleversée ", reste cependant un magnifique exercice esthétique, poétique et de traduction, tout en témoignant de la « fascination érudite » de cette époque pour les " rhapsodies premières » (analyses de P. Chuvin, p. 41-59, de P. Payen, p. 95-112, et de S. Rabau, p. 113-127) et pour les prétendues origines phéniciennes de la thalassocratie méditerranéenne (C. Bonnet, p. 61-78). En cela, Bérard a été influencé par la science allemande qu'il a cependant publiquement critiquée dans un virulent pamphlet paru en 1917 (M. Espagne, p. 79-93). Ses voyages nautiques sur les traces d'Ulysse ont par ailleurs contribué à faire de la photographie un auxiliaire de l'archéologie et de la géographie historique, grâce à sa collaboration avec Frédéric Boissonnas (1858-1948) dont les archives photographiques sont en cours d'étude par E. Sohier (p. 129-154, avec de belles reproductions) ${ }^{2}$.

2 La deuxième partie de l'ouvrage développe les engagements de l'intellectuel et du publiciste (p. 275-291, contribution de S. Basch sur Bérard dans "sa génération » littéraire). Dès les années 1890, l'helléniste prend position sur la "Question d'Orient ", décrivant et commentant la complexité et les bouleversements de l'Empire ottoman (H. Laurens, p.169-187; G. Tolias, p. 253-262, sur la " question macédonienne »), défend la cause arménienne (G. Pécoud, p. 189-208 et E. Eldem, p. 209-251) et signe en 1898 la pétition parue dans l'Aurore en faveur de Dreyfus à la suite du J'accuse de Zola (P. Simon-Nahum, p. 263-273) ; secrétaire général de la Revue de Paris de 1904 à 1911, il y écrit des articles de politique étrangère qui donnent lieu à des ouvrages comme $L a$ révolte de l'Asie (1904) ou Révolutions de la Perse (1910). Élu par les Jurassiens au Sénat de 1920 à 1931, il y préside les Commissions des Affaires étrangères et de l'Enseignement ; à ce titre, il mène de nombreuses actions en faveur de l'éducation - y compris dans sa région d'origine - et défend l'influence française dans les dossiers internationaux « de la Suisse à la Tunisie » et au Moyen-Orient (J. Garrigues, p. 293-302). Il faudrait même dire jusqu'à l'Afghanistan car Bérard, en relation avec des condisciples athéniens également engagés (par exemple G. Deschamps membre de la Chambre des députés), a dans les années 1920 encouragé la création d'une ambassade à Kaboul et celle de la Délégation archéologique française en Afghanistan, ce dont témoigne un superbe discours reproduit dans les Débats parlementaires ${ }^{3}$.

Les deux aspects, histoire et archéologie antiques et engagement, ne sont pas contradictoires, mais étroitement liés. On retrouve chez de nombreux savants de cette époque, tels les frères Reinach et des orientalistes comme Paul Pelliot ou Sylvain Lévi ${ }^{4}$, cette attention portée à travers les cultures passées aux sociétés contemporaines, dans un monde occidental - fascinant pour nous aujourd'hui - où se côtoient universitaires, politiques, diplomates, artistes et hommes de lettres. L'enquête géographique et l'héritage de l'hellénisme constituent deux autres fils conducteurs de l'œuvre de Bérard 
qui peuvent être suivis également dans d'autres parcours savants de cette fin du XIX siècle et premier tiers du $\mathrm{xx}^{\mathrm{e}} \mathrm{s}$. C'est pourquoi il est dommage que ce volume, clos par une bibliographie sélective (thématique et chronologique) de V. Bérard et des résumés bilingues (français-anglais), n'offre pas un index qui aurait permis des accès plus faciles à la multiplicité des lieux, personnes et institutions fréquentées par V. Bérard, ainsi qu'aux notions traitées par ce dernier.

Par leur mise en contexte nuancée de l'érudit et de son œuvre prolifique, ces actes de colloque intéresseront un public varié. On notera pour finir la parution, après celle-ci, de l'essai romanesque de Sophie Rabau ${ }^{5}$ sur Victor Bérard : signe que sa quête d'Ulysse est elle-même devenue source d'inspiration littéraire autant qu'historique.

\section{NOTES}

1. La Métamorphose des ruines. L'influence des découvertes archéologiques sur les arts et les lettres (1870-1914) et avec A. FARNOUX, Le Voyage en Grèce. Du périodique de tourisme à la revue artistique. 1934-1939, Athènes, École française d'Athènes, resp. 2004 et 2006 (CHMC 4 et 5).

2. E. Sohier vient également de publier à ce sujet « Ré-imaginer la Méditerranée avec l'Odyssée, la carte et la photographie. Victor Bérard, un géographe sur les traces d'Ulysse ", Annales de géographie 709-710, 2016, p. 333-359.

3. Débats parlementaires. Sénat 1923, p. 381-382 : cf. A. FENET, « L'École française d'Athènes et la Délégation archéologique française en Afghanistan : hellénistes et indianistes unis pour une même cause (1922-1924) », in C. Bonnet, V. Krings, C. Valenti (dir.), Connaître l'Antiquité. Individus, réseaux, stratégies du XVIII ${ }^{e}$ au XXI siècle, Rennes, PUR, 2011, p. 121-139.

4. Cf. comptes rendus in Anabases : 10, 2009, p. 281-282 ; 22, 2015, p. 274-275; 7, 2002, p. 275-276.

5. B comme Homère : l'invention de Victor B, Toulouse, Anacharsis, 2016.

\section{AUTEURS}

\section{ANNICK FENET}

UMR 8546 AOROC (ENS-CNRS)/ PLH-ERASME

annick.fenet@mae.u-paris10.fr 